\title{
Retalho supramaleolar de fluxo reverso: aplicações clínicas
}

\author{
Supramalleolous flap of reverse flow: clinical applications
}

Juliano Candido Batista ${ }^{1}$

Trabalho realizado na Santa Casa de Misericórdia de Passos, Passos, MG, Brasil.

Trabalho apresentado para ascensão à categoria de membro titular da SBCP.

Artigo submetido pelo SGP (Sistema de Gestão de Publicações) da RBCP.

Artigo recebido: 7/11/2010 Artigo aceito: 15/3/2011

\begin{abstract}
RESUMO
As regiões distais do membro inferior, incluindo o terço inferior da perna e os pés, são áreas muito propensas a perda de partes moles por trauma e lesões tróficas. A posição anterior da tíbia, com sua cobertura pouco espessa e vulnerável, além da grande quantidade de tendões, que não podem permanecer expostos, exigem uma cobertura cutânea rápida $\mathrm{e}$, ao mesmo tempo, complexa. A situação em relação à direção do fluxo sanguíneo, a escassez de ventres musculares para retalhos e pele pouco elástica para retalhos randomizados viáveis complicam esta situação. No passado, retalhos com transferência intermediária foram utilizados; assim como os de perna cruzada, "cross leg", ainda são, com desvantagens importantes: dependem de mais de um tempo cirúrgico, geram muito desconforto ao paciente e nem sempre são eficazes. A microcirurgia tornou-se uma opção que contribui muito para cobertura de lesões neste aspecto, porém, depende de equipe com treinamento e material especializado. As áreas doadoras são maiores, podem causar relativo déficit funcional e utilizam troncos vasculares maiores. Os retalhos fasciocutâneos de fluxo reverso podem contribuir para a cobertura de lesões pequenas e médias nesta localização, com sequelas funcionais e estéticas menores; e menor tempo cirúrgico. Constitui eficiente opção cirúrgica por sua facilidade, segurança e versatilidade. Neste estudo, temos o objetivo demonstrar o retalho supramaleolar de fluxo reverso utilizado em 4 casos, com aplicações em situações diferentes, com resultados satisfatórios de fácil execução e reprodução.
\end{abstract}

Descritores: Retalhos cirúrgicos. Traumatismos da perna. Traumatismos do tornozelo. Extremidade inferior/cirurgia.

\begin{abstract}
The regions of the distal lower limb, including the $1 / 3$ lower leg and foot areas are very prone to loss of soft tissue for trauma and ulcerations. The anterior position of the tibia, with its coverage slightly thick and vulnerable, besides the large amount of tendons, which can not remain exposed, requiring skin coverage quickly and simultaneously complex. The situation with respect to the direction of blood flow, lack of muscle bellies for flaps and skin flaps for inelastic randomized viable complicates this situation. In the past, with intermediate transfer flaps were used, as the leg cross, are still with major drawbacks: they rely on more than one occasion, generate a lot of discomfort to the patient and are not always effective. Microsurgery has become an option that helps a lot to cover injuries this point, however, depends on the team with training and specialized equipment. Donor areas are larger, can cause functional impairment and use on major vascular trunks. The fasciocutaneous flaps of reverse flow can contribute to the coverage of small and medium lesions in this location, with minor aesthetic damage and functional and less time for surgery. It constitutes effective surgical option for its ease, safety and versatility. In this study we demonstrate supramalleolous flap of reverse flow used in 4 cases, with applications in different situations, with satisfactory results easy and reproduction.
\end{abstract}

Keywords: Surgical flaps. Leg injuries. Ankle injuries. Lower extremity/surgery.

1. Cirurgião plástico, membro titular da Sociedade Brasileira de Cirurgia Plástica, médico da Santa Casa de Misericórdia de Passos - Minas Gerais, Brasil; Ex - residente do Serviço de Cirurgia Plástica da Universidade Federal do Triângulo Mineiro, Uberaba, MG,.Brasil. 


\section{INTRODUÇÃO}

Estudos da distribuição dos vasos e do fluxo sanguíneo possibilitaram avanços no tratamento de lesões cutâneas.

À medida que ocorreu evolução no salvamento de partes de extremidades, incluindo soluções ortopédicas para traumas mais complexos, houve aumento da necessidade de reparação em locais mais difíceis, onde estruturas não podiam aguardar melhora da ferida para cobertura com simples enxerto de pele, e os retalhos mais simples também não se tornavam viáveis. O tratamento destas lesões estimulou a criação de retalhos de transferência intermediária, já nos tempos mais remotos. A impossibilidade de reconstruções com retalhos locais fomentou o estudo da microcirurgia com suas aplicações.

A partir dos trabalhos de Pontén ${ }^{2}$, em 1981, os retalhos fasciocutâneos tornaram-se alternativa aos retalhos microcirúrgicos.

Desde então, vários estudos têm demonstrado distribuição de vascularização constante, predominante nestes retalhos e suas aplicações clínicas com segurança em todo o corpo ${ }^{3}$.

A posição distal de algumas lesões em membros dificultava e impossibilitava a aplicação de retalhos de fluxo direto. A descoberta do retalho chinês de fluxo reverso foi uma solução para as lesões de extremidade superior, do mesmo modo que o retalho de artéria interóssea posterior, com ponto de rotação baseados nas anastomoses do punho. No membro inferior, a posição apendicular e distal do $1 / 3$ distal da perna, tornozelo e dorso de pé, e a dinâmica da região facilitam os traumas, e as lesões nestes locais ainda são um desafio para a cirurgia plástica. Existem retalhos semelhantes aos do membro superior, como o baseado na artéria tibial anterior ${ }^{4}$ e o retalho sural. Consideramos o retalho supramaleolar análogo ao retalho da artéria interóssea posterior.

O fluxo arterial reverso é mantido e explicado pelas anastomoses em torno do tornozelo. Já o fluxo venoso, alvo de discussões, é obtido pela insuficiência valvar através do próprio gradiente de pressão, pelas veias comunicantes, capilares e colaterais e pela denervação das valvas durante a liberação e a elevação do pedículo ${ }^{4,5}$. Isto explica o edema temporário dos retalhos reversos.
Neste trabalho, demonstramos quatro casos clínicos com aplicações distintas do retalho supramaleolar lateral de fluxo reverso, com discussão de suas vantagens e facilidades.

\section{MÉTODO}

Foram realizados 4 retalhos supramaleolares de fluxo reverso, com lesões de locais diferentes, em 4 pacientes, no período de maio de 2008 a março de 2010. As cirurgias não foram realizadas ao mesmo tempo em que procedimentos ortopédicos. Nenhum dos casos apresentados apresentava sinais clínicos de doença arterial periférica. As informações referentes aos casos clínicos encontram-se na Tabela 1.

\section{Técnica Cirúrgica}

A técnica do retalho supramaleolar lateral é muito bem descrita por Masquelet e Gilbert ${ }^{5}$, geralmente empregado com pedículo de base distal. Tem como base a anastomose da arcado arterial em torno do tornozelo com ramo perfurante da artéria fibular, que emerge da membrana interóssea a aproximadamente $5 \mathrm{~cm}$ do maléolo lateral. Esta anastomose emite ramos para pele nesta altura e fazem anastomose com o plexo que acompanha o nervo fibular superficial, que por sua vez constitui território septocutâneo da artéria tibial anterior ${ }^{6}$.

Não foi utilizado ultrassom Doppler para identificação no pré-operatório em nenhum dos casos. Foi realizada marcação da previsão da localização da artéria perfurante no local de depressão palpável, localizada no terço distal do espaço entre a tíbia e a fíbula. Este ponto foi incluído no retalho, que teve como limite anterior o tendão do músculo tibial anterior e, posterior, a face medial da fíbula, sem expor o osso. A porção proximal do retalho pode ser demarcada até no meio da perna.

Todos os pacientes foram submetidos a raquianestesia. Posicionado coxim sob o glúteo do mesmo lado, para facilitar a rotação interna da perna. As lesões foram submetidas a desbridamento pseudotumoral, até atingir tecido viável. O retalho demarcado foi dissecado sem aplicação de torniquete, de modo subfascial anterior e posteriormente, mantendo o septo, e de proximal para distal, preservando o nervo fibular superficial,

Tabela 1 - Caracterização da casuística.

\begin{tabular}{l|c|c|c|c}
\hline \multicolumn{1}{c|}{ Paciente } & $\begin{array}{c}\text { Idade } \\
\text { (anos) }\end{array}$ & Trauma & $\begin{array}{c}\text { Cirurgia } \\
\text { (minutos) }\end{array}$ & $\begin{array}{c}\text { Internação } \\
\text { (dias) }\end{array}$ \\
\hline 1 - JAFO & 40 & $\begin{array}{c}\text { Fratura exposta em antepé esquerdo } \\
\text { Exposição de tendões extensores }\end{array}$ & 4 \\
\hline 2 - NJA & 39 & $\begin{array}{c}\text { Trauma em pedra, com necrose de pele em tornozelo e } \\
\text { exposição de tendão fibular }\end{array}$ & 65 \\
\hline 3 - WJVD & 11 & Fratura luxação exposta III b de tornozelo direito & 115 & 13 \\
\hline 4 - HJL & 44 & Fratura exposta de perna direita com refratura & 70 & 6 \\
\hline
\end{tabular}

*Maior distância da cidade de origem com dificuldade de transporte. 
que foi liberado da face posterior da fáscia, preservando-o. Os vasos do septo foram ligados proximalmente e a perfurante identificada e ligada quando necessário. O septo foi liberado da fíbula até permitir a transposição do retalho. Para coberturas distais, até o dorso do pé; o ponto de rotação distal foi o canal do tarso, por dissecção do pedículo através de incisão no retináculo.

O retalho foi transposto através de incisão separada e suturado às bordas da ferida. Não passa através de túnel para atingir o local receptor, para evitar prejuízo da irrigação devido às características locais. A dissecção não é microvascular. O nervo fibular superficial é sepultado sob os músculos extensor longo dos dedos e fibular longo. A área doadora do retalho foi coberta por enxerto de pele parcial. Deve-se ter cuidado com o curativo compressivo sobre o enxerto, para não comprimir o retalho.

As Figuras 1 a 4 ilustram os casos deste estudo.

\section{RESULTADOS}

Observou-se cobertura eficaz e estável das lesões do terço inferior da perna, tornozelo e dorso do pé. Nenhum dos pacientes apresentou deiscência e/ou infecção pós-operatória. Não houve necrose em nenhum dos retalhos, exceto por discreta epiteliolise de borda no caso 4, por provável compressão da área do enxerto, que foi resolvida com epitelização espontânea do local.

O tempo cirúrgico variou de 65 a 135 minutos, conforme a necessidade de dissecção distal do pedículo.
Todos os retalhos apresentaram edema temporário no pós-operatório, com resolução espontânea.

\section{DISCUSSÃO}

Perdas cutâneas da extremidade inferior podem expor ossos, articulações e tendões. Os retalhos musculares têm sua aplicação bem definida nos casos de osteomielite, por oferecer suprimento sanguíneo eficaz nas áreas afetadas, sobretudo no terço superior (gastrocnêmio) e médio (sóleo). O terço distal já necessita de tratamento com maior complexidade, como o retalho de hemi-sóleo reverso, para sua porção mais proximal, que constitui um retalho de risco, devido a sua irrigação tipo II. Os retalhos microcirúrgicos de grande dorsal e reto abdominal, dentre outros, são uma opção para cobertura no terço inferior da perna e do pé, porém levam a relativa restrição de função e resultados estéticos piores, além de serem tecnicamente mais difíceis.

O terço inferior da perna, especificamente, é um local de estruturas com função dinâmica (tendões e articulação do tornozelo) e os retalhos menos espessos, com fibrose menor e, portanto, com mais elasticidade, permitem um resultado funcional e estético melhor em áreas doadoras e receptoras ${ }^{7}$. A partir dos trabalhos de Pontén ${ }^{2}$, em 1981, com estudo dos retalhos fasciocutâneos, com maior vascularização por inclusão da fáscia, houve padronização destes retalhos e
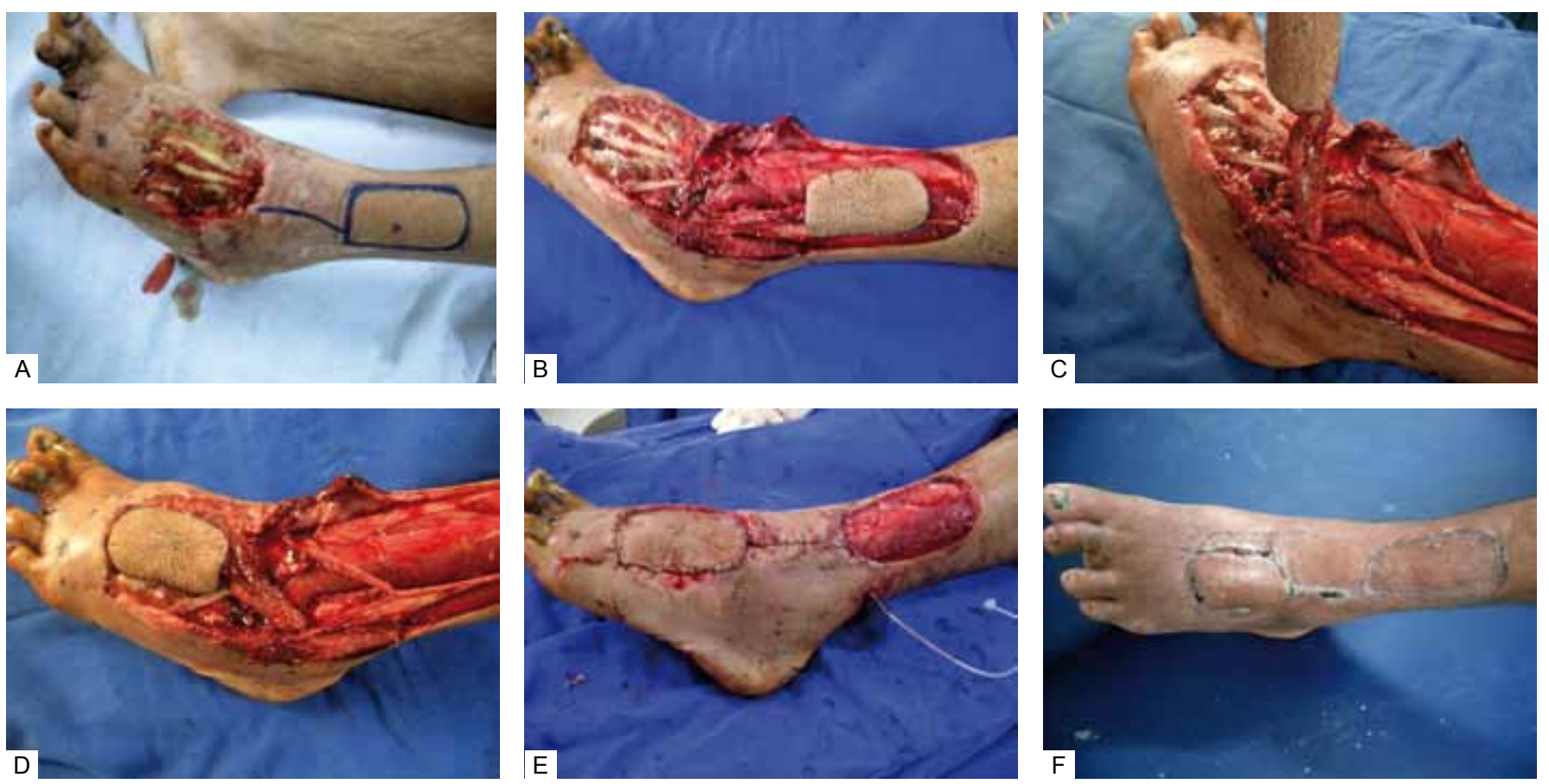

Figura 1-A: Exposição de tendões extensores do pé esquerdo. Demarcação dos limites do retalho e de perfurante em depressão palpável.

$\boldsymbol{B}, \boldsymbol{C}$ e D: Liberação do retalho com pedículo ao nível do canal do tarso, elevação e transposição do retalho, preservando nervo fibular superficial. E: Retalho posicionado. F: Resultado final, cobertura de área doadora com enxerto de pele parcial. 

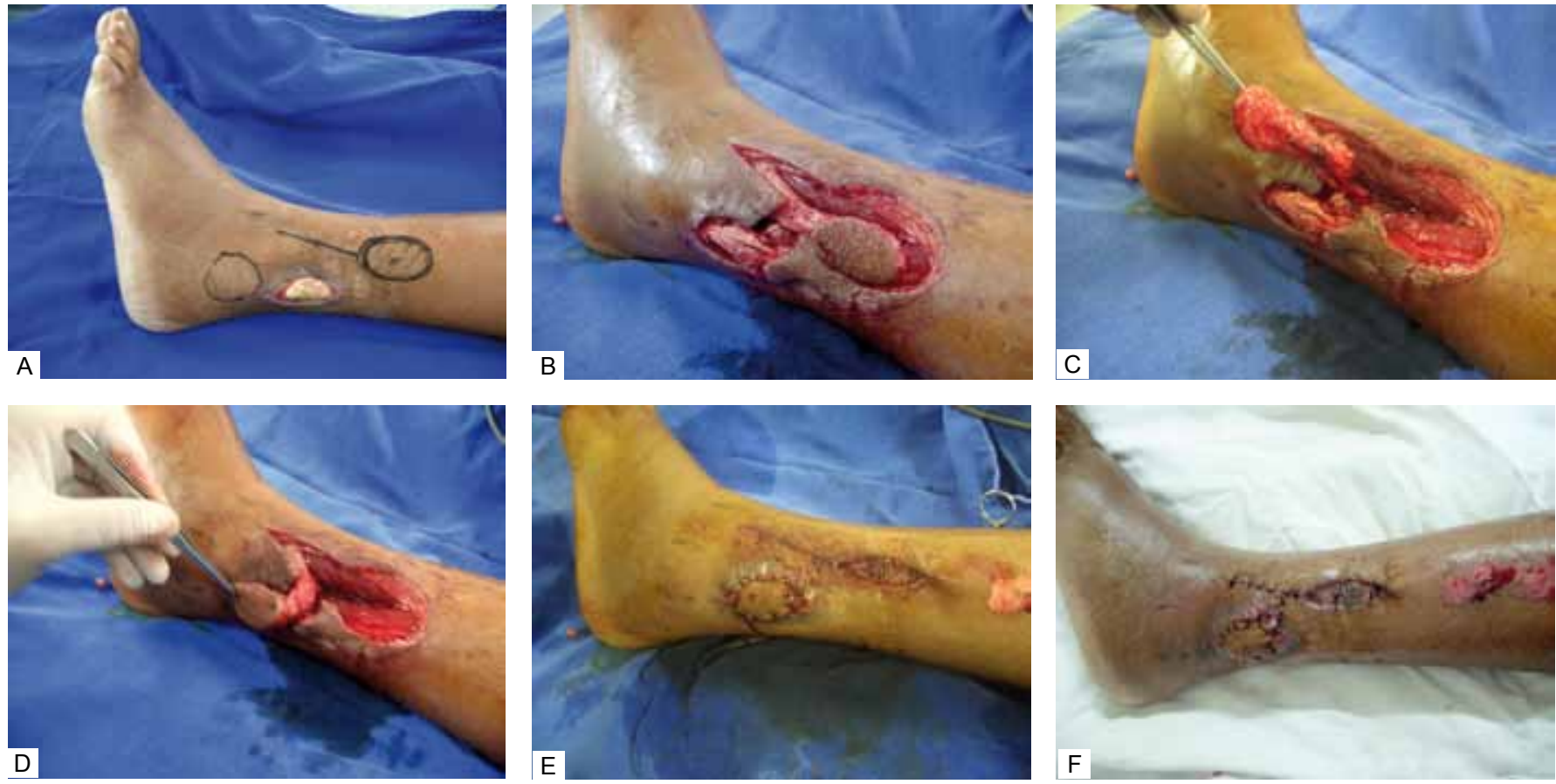

Figura 2 - A: Marcação do retalho para cobertura de exposição de tendão fibular, área inferior demarcando maléolo lateral.

$\boldsymbol{B}, \boldsymbol{C}$ e D: Liberação do retalho com pedículo ao nivel do canal do tarso, elevação e transposição do retalho, preservando nervo fibular superficial. $\boldsymbol{E}$ : Cobertura de área doadora com enxerto de pele parcial. $\boldsymbol{F}$ : Resultado tardio.
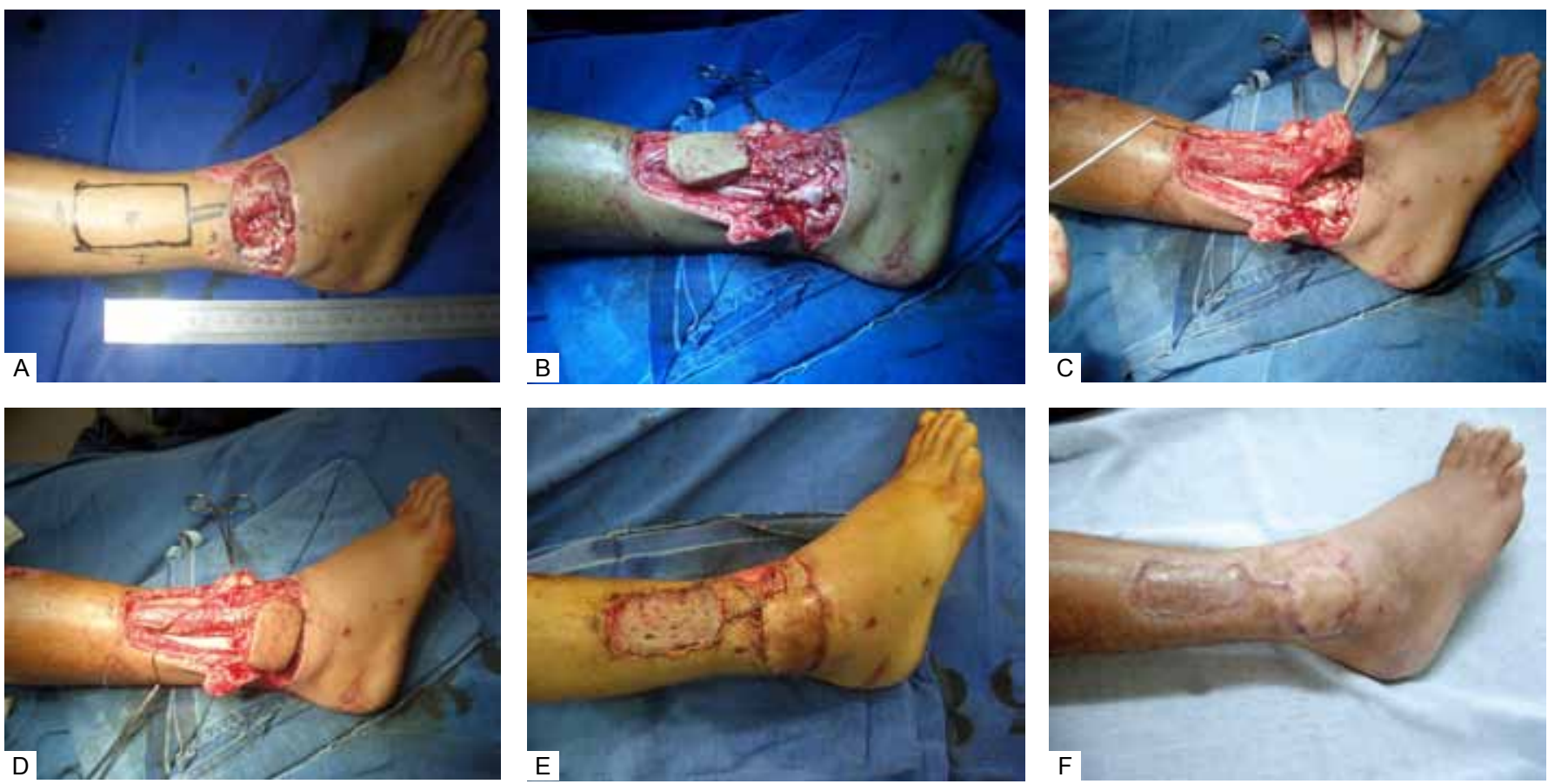

Figura 3 - A: Exposição óssea e de material de síntese em fratura de malélo lateral direito e demarcação dos limites do retalho.

B: Liberação do retalho. C: Elevação do retalho. D: Transposição do retalho preservando nervo fibular superficial. $\boldsymbol{E}$ : Retalho posicionado e cobertura de área doadora com enxerto de pele parcial. $\boldsymbol{F}$ : Resultado tardio. 

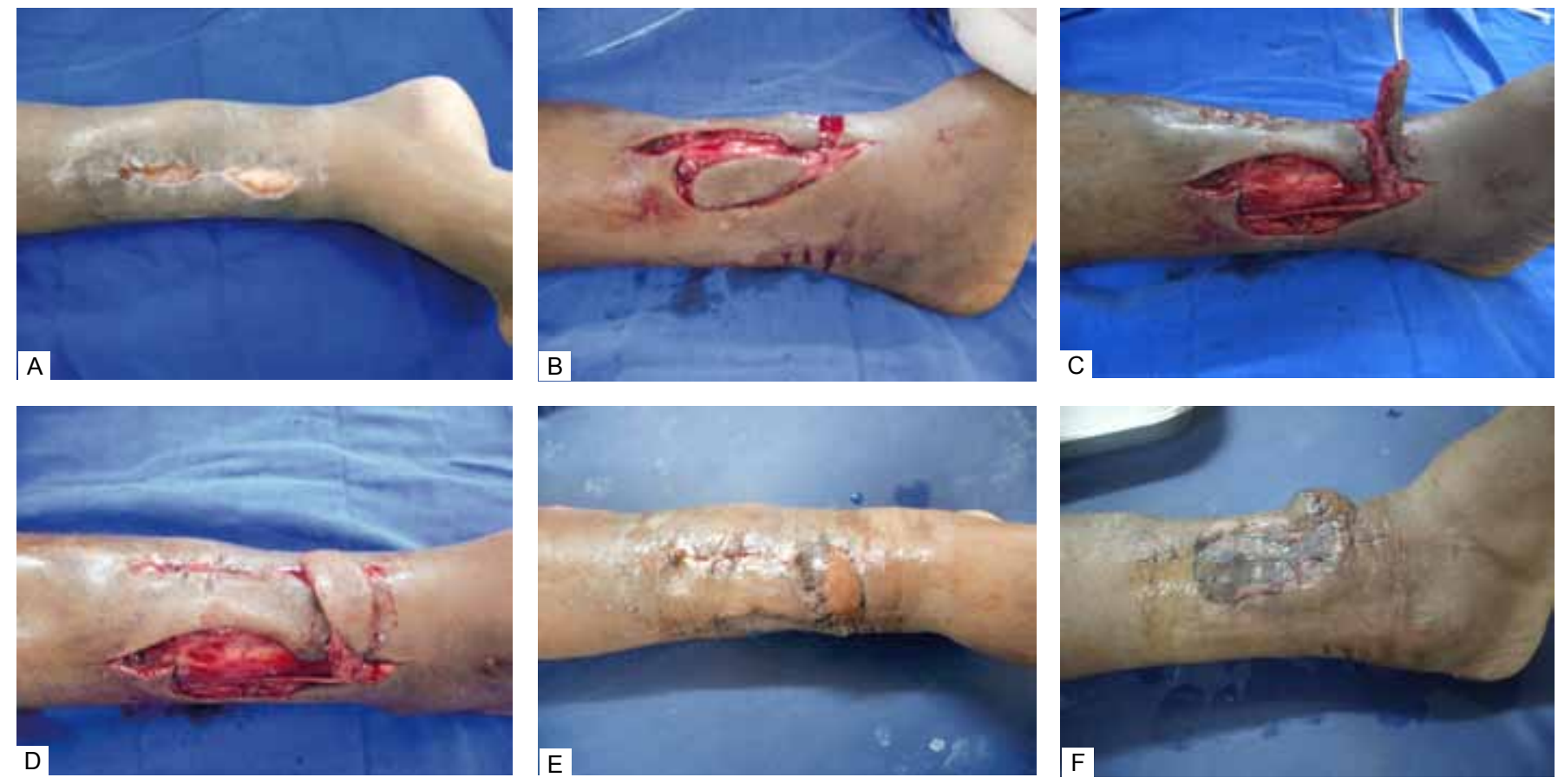

Figura 4 - A: Exposição de tendão tibial anterior e tíbia. B e C: Liberação e transposição do retalho. D: Retalho transposto para cobertura do tendão tibial anterior e aproximação para cobertura de tíbia. E: Epiteliólise de borda do retalho por compressão do enxerto adjacente. $\boldsymbol{F}$ : Aplicação de enxerto em área doadora no mesmo tempo cirúrgico.

aumento na sua indicação para cobertura, sobretudo nas regiões distais do membro inferior ${ }^{8,9}$. Em 1991, Hyakusoku descreve o retalho em hélice, o propeller flap, que pode ser rodado em $180^{\circ}$, tendo como base a perfurante como seu eixo ${ }^{10}$. Jiga et al. ${ }^{11}$ demonstraram versatilidade deste tipo de retalho, inclusive em pacientes com doença arterial obstrutiva periférica, como cobertura de úlceras após revascularização, obtendo sucesso. O consenso Gent define que retalhos perfurantes são compostos de pele e subcutâneo, sendo nutridos por vasos perfurantes do sistema vascular profundo, que atravessam para superfície passando mais frequentemente através de músculos e septo intermusculares ${ }^{12}$.

Artérias perfurantes são distribuídas aleatoriamente na perna, algumas regiões têm mais frequentes. Whetzel, Barnard e Stokes descreveram 10 territórios fasciocutâneos preditíveis baseados nos septos intermusculares ${ }^{6}$ e Schaverien Saint-Cyr analisaram e descreveram posições de predomínio dessas perfurantes, sendo encontrados em 3 distintos intervalos de $5 \mathrm{~cm}$ em relação à linha intermaleolar, sendo de 4 a $9 \mathrm{~cm}, 13$ a $18 \mathrm{~cm}$ e 21 a 26 $\mathrm{cm}$, considerando distância de pernas estudadas de 34 a $41 \mathrm{~cm}^{13}$. Estes estudos têm utilidade na programação de retalhos, principalmente para cobertura de $1 / 3$ distal do membro inferior ${ }^{14}$. As demarcações podem ser de diferentes formas, de avanço e de rotação através de seu ponto pivô, permitindo a confecção de retalho tipo hélice (propeller) com rotação de $180^{\circ}$, alcançando áreas mais distais por meio da ampliação dos limites proximais, que é ainda ponto de controvérsias ${ }^{15}$. As indicações são sobrepostas àquelas do retalho sural, exceto que este pode ser adicionado por componente muscular para cobertura de área de calcâneo, oferecendo maior espessura ${ }^{16}$.

As taxas de sucesso demonstram ser alternativa aos retalhos microcirúrgicos, que são mais complexos, demandam maior tempo cirúrgico, treinamento e mantêm os riscos de perda.

O eco Doppler permite definir quantitativa e qualitativamente os vasos e planejar o tipo de retalho, diminuindo complicações, no entanto, não é essencial ${ }^{10,17}$. A consistência das perfurantes nestes intervalos pode ser útil para planejar opções de retalhos, podendo dispensá-lo ${ }^{18}$. Nestes casos apresentados, utilizamos da anatomia e da palpação do ponto de depressão palpável no terço distal, entre a tíbia e a fíbula para programação do retalho.

Dentre as vantagens desse tipo de retalho: artérias e músculos preservados; não há necessidade de microanastomose; retalho é rápido; simula a área receptora em textura, espessura, pigmentação e flexibilidade ${ }^{13}$.

As complicações que podem ocorrer são as mesmas de qualquer tipo de retalho. Erros técnicos na confecção podem levar a isquemia, com necrose parcial ou total. 
A fáscia é menos resistente à infecção que os retalhos musculares, por isso é importante ter considerações sobre as condições locais e indicações para sua realização ${ }^{19}$.

\section{CONCLUSÃO}

Os retalhos microcirúrgicos certamente são uma ótima opção para o tratamento de lesões complexas, sobretudo de extensões maiores nos membros inferiores. Porém, tem havido certa preocupação em oferecer resultados mais estéticos em cirurgias reparadoras e até retalhos microcirúrgicos com características mais próximas da região receptora ${ }^{20}$.

Os retalhos fasciocutâneos ampliaram as possibilidades de cobertura cutânea adequada de lesões de pequenas e médias extensões em regiões onde é mais difícil, como nas regiões distais da perna, tornozelo e pé ${ }^{21}$. Os retalhos menos espessos oferecem características ideais (like to like): cor, espessura e textura semelhantes; ter pedículo constante preditível e reprodutível, aceitável morbidade de área doadora; evita sacrifício de artéria e músculos e, além de oferecer tempos cirúrgicos com tempos menores, menos complexos (incluindo o tipo de anestesia) ${ }^{7,13}$, com riscos semelhantes aos de outros retalhos.

A fáscia dificulta a rotação e, às vezes, necessita de corte delicado posteriormente, para maior liberação e menor dificuldade para rotação ${ }^{2}$. A extensão do retalho supera o tamanho da lesão por ocorrer formação de orelhas de pele durante a transposição, que geralmente são reparadas em $2^{\circ}$ tempo, principalmente nas lesões mais distantes de sua base. Este problema com a rotação não ocorre nos retalhos perfurantes em hélice assimétrica (propeller flaps), pois têm como ponto de rotação somente os vasos, que permitem sua rotação até $180^{\circ}$ e uma parte da área doadora é coberta pelo componente menor da hélice ${ }^{22}$.

$\mathrm{O}$ uso de retalhos de pedículo distal em ilha, utilizando-se de seu pedículo das artérias do plexo supramaleolar, liberando e seccionando o septo proximalmente, permite a transposição do retalho, sem aumento de seu comprimento (o que ocorre mesmo nos propeller flaps), alcançando áreas mais distais, sem aumentar a extensão da área doadora, melhorando o resultado estético ${ }^{9}$, sem preocupação com lesões de vasos e nervos importantes.

O retalho supramaleolar demonstra eficácia de aspectos ideais para coberturas de lesões distais de perna, tornozelo e regiões do pé, de pequenas e médias proporções. É de fácil reprodutividade, dissecção anatômica, sem interferir na possibilidade de demarcação de outros retalhos. Tem sua aplicação como alternativa nos centros distantes daqueles de disponibilidade técnica e laboratorial para microcirurgia.

\section{REFERÊNCIAS}

1. Ferreira LM, Andrews JM, Laredo Filho J. Retalho fasciocutâneo de base distal: estudo anatômico e aplicação clínica nas lesões do terço inferior da perna e tornozelo. Rev Bras Ortop. 1987;22(5):127-31.

2. Pontén B. The fasciocutaneous flap: its use in soft tissue defects of the lower leg. Br J Plast Surg. 1981;34(2):215-20.

3. Bloch RJ, Retalhos fasciais, fasciocutâneos e osteomiofasciocutâneos. Rio de Janeiro:Revinter;2002. 319p.

4. Wee JT. Reconstruction of the lower leg and foot with the reversepedicled anterior tibial flap: preliminary report of a new fasciocutaneous flap. Br J Plast Surg. 1986;39(3):327-37.

5. Masquelet AC, Gilbert A. Atlas colorido de retalhos na reconstrução dos membros. Rio de Janeiro:Revinter;1997. p.148-57.

6. Whetzel TP, Barnard MA, Stokes RB. Arterial fasciocutaneous vascular territories of the lower leg. Plast Reconstr Surg. 1997; 100(5):1172-83.

7. Demirtas Y, Kelahmetoglu O, Cifci M, Tayfur V, Demir A, Guneren E. Comparison of free anterolateral thigh flaps and free musclemusculocutaneous flaps in soft tissue reconstruction of lower extremity. Microsurgery. 2010;30(1):24-31.

8. Monteiro Jr AA, Morais J, Figueiredo, JCA, Amaral AB, Kalô FJ. Cirurgia reparadora do membro inferior. In: Mélega JM, ed. Cirurgia reparadora de tronco e membros. Cirurgia Plástica Fundamentos e Arte. Rio de Janeiro:Guanabara Koogan;2004. p.714.

9. Almeida OM, Monteiro AA Jr, Neves RI, Lemos RG, Braz JC, Brechtbuhl ER, et al. Distally based fasciocutaneous flap of the calf for cutaneous coverage of the lower leg and dorsum of the foot. Ann Plast Surg. 2000;44(4):367-73.

10. Pignatti M, Pasqualini M, Governa M, Bruti M, Rigotti G. Propeller flaps for leg reconstruction. J Plast Reconstr Aesthet Surg. 2008;61(7):777-83.

11. Jiga LP, Barac S, Taranu G, Blidisel A, Dornean V, Nistor A, et al. The versatility of propeller flaps for lower limb reconstruction in patients with peripheral arterial obstructive disease: initial experience. Ann Plast Surg. 2010;64(2):193-7.

12. Blondeel P, Van Landuyt K, Monstrey SJ, Hamdi M, Matton GE, Allen RJ, et al. The "Gent" consensus on perforator flap terminology: preliminary definitions. Plast J Surg. 2003;112(5):1378-83.

13. Schaverien M, Saint-Cyr M. Perforators of the lower leg: analysis of perforator locations and clinical application for pedicled perforator flaps. Plast Reconstr Surg. 2008;122(1):161-70.

14. Monteiro Júnior AA, Alonso N. Repair of cutaneous losses on the leg and foot with the distally based fasciocutaneous flap. Reparação de perdas cutâneas na perna e no pé com retalho fasciocutâneo de pedículo distal. Rev Soc Bras Cir Plást. 1991;6(1/2):33-40.

15. Rezende MR, Rabelo NT, Wei TH, Mattar Junior R, Paula EL, Zumiotti AV. Skin coverage of the middle-distal segment of the leg with a pedicled perforator flap. J Orthop Trauma. 2010;24(4):236-43.

16. Chang SM, Zhang K, Li HF, Huang YG, Zhou JQ, Yuan F, et al. Distally based sural fasciomyocutaneous flap: anatomic study and modified technique for complicated wounds of the lower third leg and weight bearing heel. Microsurgery. 2009;29(3):205-13.

17. Panagiotopoulos K, Soucacos PN, Korres DS, Petrocheilou G, Kalogeropoulos A, Panagiotopoulos E, et al. Anatomical study and colour Doppler assessment of the skin perforators of the anterior tibial artery and possible clinical applications. J Plast Reconstr Aesthet Surg. 2009;62(11):1524-9.

18. Tajsiç N, Winkel R, Hoffmann R, Husum H . Sural perforator flap for reconstructive surgery in the lower leg and the foot: a clinical study of 86 patients with post-traumatic osteomyelitis. J Plast Reconstr Aesthet Surg. 2009;62(12):1701-8. 
19. Robertson KM, Woodberry KM, Flaps, fasciocutaneous flaps. http:// emedicine.medscape.com/article/1284631-overview

20. Kim NG, Lee KS, Choi TH, Kim JS, Choi JH, Jang PY, et al. Aesthetic reconstruction of lower leg defects using a new anterolateral lower leg perforator flap. J Plast Reconstr Aesthet Surg. 2008;61(8):934-8.
21. Amarante J, Costa H, Reis J, Soares R. A new distally based fasciocutaneous flap of the leg. Br J Plast Surg. 1986;39(3): 338-40.

22. Teo TC. Reconstrucción de la extremidad inferior con colgajos de perforantes locales. Cir Plást Iberlatinamer 2006;32(4).

\title{
Correspondência para: Juliano Candido Batista
}

\author{
Rua Águas Formosas, 182 - Umuarama - Passos, MG, Brasil - CEP 37902-352
}

E-mail: juliano.candido@terra.com.br 